This paper is part of the Proceedings of the $3^{\text {rd }}$ International Conference on Design,

\title{
Non-drinking water self-sufficiency of residential buildings utilizing rainwater harvesting
}

\author{
J. $\operatorname{Kim}^{1} \&$ A. Latos ${ }^{2}$ \\ ${ }^{1}$ Taubman College of Architecture, University of Michigan, USA \\ ${ }^{2}$ Department of Civil Engineering, University of Michigan, USA
}

\begin{abstract}
Rainwater harvesting is a strategy for reducing a building's reliance on municipal water. New residential buildings as well as large commercial buildings are increasingly equipped with rainwater collection systems. It is uncertain, however, how significant a role rainwater harvesting plays in achieving a building's water self-sufficiency. How effective is rainwater harvesting in various climatic zones? Is water self-sufficiency an achievable goal? This paper examines the water selfsufficiency of residential buildings that utilize rainwater harvesting. The test building is a two story single-family house with a population of four residents. The water consumption and rainwater harvesting potential of this standard house were analysed in a range of climatic zones across the US. The continental US is a microcosm of the world's climates spanning from the arid desert to the humid savanna, from the sub-tropical south to the frigid north. Based on the data published by the United States Geological Surveys (USGS), water consumption of the standard house in 13 test cities was analyzed. Next, the volume of rainwater harvested from the roof of this standard home was estimated. The National Oceanic and Atmospheric Administration (NOAA) 30-year average precipitation data were used in estimating the volume of harvested rainwater. From this study, it was found that rooftop rainwater harvesting can provide at most $25 \%$ water selfsufficiency only in subtropical climates. In arid climates, the self-sufficiency was approximately $5 \%$ or less, even in rainy months. Drastically conserving water through change in occupant consumption patterns, supplemented with rainwater harvesting, is essential in achieving a building's water self-sufficiency.

Keywords: sustainability, climate, rainwater harvesting, water self-sufficiency, catchment systems.
\end{abstract}




\section{Background}

Water is a valuable resource, necessary for all regardless of location or socioeconomic status. The majority of developed countries rely on municipal water systems, consuming as much as necessary, with used water piped back to a water plant for treatment. Remote locations seldom rely on municipal water, with individual homes having their own treatment systems. The most common method for rural homes is drawing groundwater from a well. A second method to produce potable water onsite exists through rainwater harvesting. Precipitation is collected from building or ground surfaces, and after treatment can be used as any potable water would. Rainwater harvesting provides an alternative method to increase a building's water self-sufficiency, reduce reliance on municipal treatment plants and water runoff. Sample et al. [1] analyze quantitatively the benefits of rainwater harvestings in reducing municipal water supply and runoff. Location-specific feasibility analyses of rainwater harvesting as an alternative sources domestic water supply reveal its varying potentials depending on the site climates [2-4].

\section{Research objective and assumptions}

The purpose of this study is to assess the feasibility of water-self-sufficient buildings in varying climates. The specific research questions include how a region's climate affects its rainwater harvesting prospect and how much rainwater harvesting can contribute to the water self-sufficiency of single-family homes across the United States.

\subsection{Research assumptions}

This study is to assess the "prospect" of rainwater harvesting in achieving water self-sufficiency of residential buildings. Thus it is the scope of this study to analyze statistically the quantities of (1) rainwater that can be harvested and (2) water being consumed in domestic buildings in various regions in the United States. By analyzing the ratio of these two quantities, the prospect of buildings' water self-sufficiency based on rainwater harvesting can be assessed.

Harvested rainwater requires varying degrees of filtration and purification depending on its use. For outdoor plant irrigation, a minimum level of filtration is needed. For indoor toilet use, a higher level of filtration that removes debris and particles is needed. For drinking use including drinking, cooking, bathing, and cloth and dish washing, the highest level of filtration and purification is required to meet the water quality standards of local and federal governments. To date, the technology for filtrating and purifying rainwater water to produce drinking use exists, but is prohibitively expensive. Thus, in this study, it was assumed that rainwater can be used in non-drinking uses, toilet flushing and outdoor landscape irrigation. 


\subsection{Test building}

The test building is a two-story, single-family home with a population of four residents. The building has a total floor area of $185.8 \mathrm{~m}^{2}\left(2,000 \mathrm{ft}^{2}\right)$ with $92.9 \mathrm{~m}^{2}$ $\left(1,000 \mathrm{ft}^{2}\right)$ for each story (see Figure 1). It has a flat roof with no eaves or overhangs, and thus, the roof rainwater catchment area is $92.9 \mathrm{~m}^{2}$. The rainwater collection efficiency of the building is assumed to be $70 \%$ by volume. This efficiency assumes water losses of $30 \%$ in the harvesting process to account for factors such as evaporation, spills, and first flush diversion. This standard house is analyzed in all test locations. The physical characteristics of the building are those of a typical American home obtained from the American Housing Survey [5].

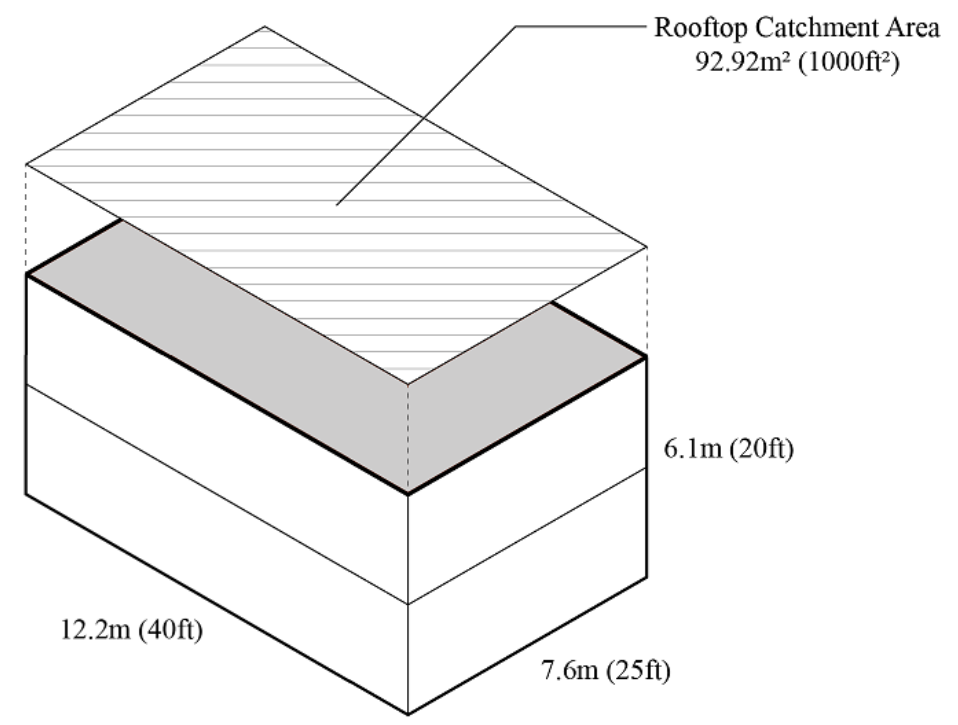

Figure 1: Standard single-family home analyzed.

\subsection{Selected climates}

The continental US is a virtual microcosm of the world's climates, spanning from arid desert to humid savanna, or from the sub-tropical south to the frigid north. Thirteen cities, each of them representing diverse climates including humid, dry, hot, cold, and various combinations, have been selected.

\section{Research methods}

The non-drinking water self-sufficiency of a building that harvesting rainwater is a function of two primary factors: the total volume of rainwater harvested and the volume of non-drinking water used by the residents. The non-drinking water selfsufficiency $S_{w-n d}$ is defined as the fraction of rainwater collected from the catchment area to the non-drinking water consumption in a building as: 


$$
S_{w-n d}=\frac{V_{p}}{V_{c-n d}}
$$

where $V_{c-n d}$ is the volume of a building's non-drinking water consumption, and $V_{p}$ is water harvested from the rainwater catchment system. The volume of rainwater harvested from a catchment area can be calculated as:

$$
V_{p}=P \cdot A_{c} \cdot e
$$

where:

$P=$ precipitation,

$A_{c}=$ catchment area projected on a horizontal plane,

$e=$ collection efficiency of the rainwater harvesting system.

\subsection{Precipitation}

Precipitation and water consumption data in the selected cities were analyzed in order to determine the feasibility of water self-sufficient buildings. The 30-year average precipitation data published by National Oceanic and Atmospheric Administration (NOAA) were used to estimate the volume of potable water able to be harvested [6].

\subsection{Residential water consumption}

The residential water consumption in the test cities was estimated from data published by the United States Geological Survey (USGS) [7]. The annual countyby-county domestic water consumption data were divided by the domestic population for an estimate of the annual per capita residential water consumption by volume. The consumption of a test home in each city was then calculated by multiplying the per capita water consumption by the standard four residents per home. The average consumption across the cities is around 300 liters ( 80 gallons) daily per capita. This domestic water consumption data obtained from our analysis is consistent with data published by the US governmental agencies [8,9]. The cities of Las Vegas and Phoenix consume the most water but also historically have received the least precipitation. This may be due primarily to the water consumption in non-essential use such as landscape irrigation and swimming pools in these desert cities. Based on the data, however, precipitation and water consumption do not have either a positive or a negative correlation (see Figure 2).

\subsection{Non-drinking water consumption}

According to the study of water uses of US households [10] conducted by American Water Works Association (AWWA) Research Foundation, indoor water uses are generally uniform across the country. The AWWA's Residential End Uses of Water (REUW) measured the end uses of water in 1,188 households in 14 North American cities. The REUW is the most comprehensive report on US residential water use available to date [11]. Based on REUW, the average US 


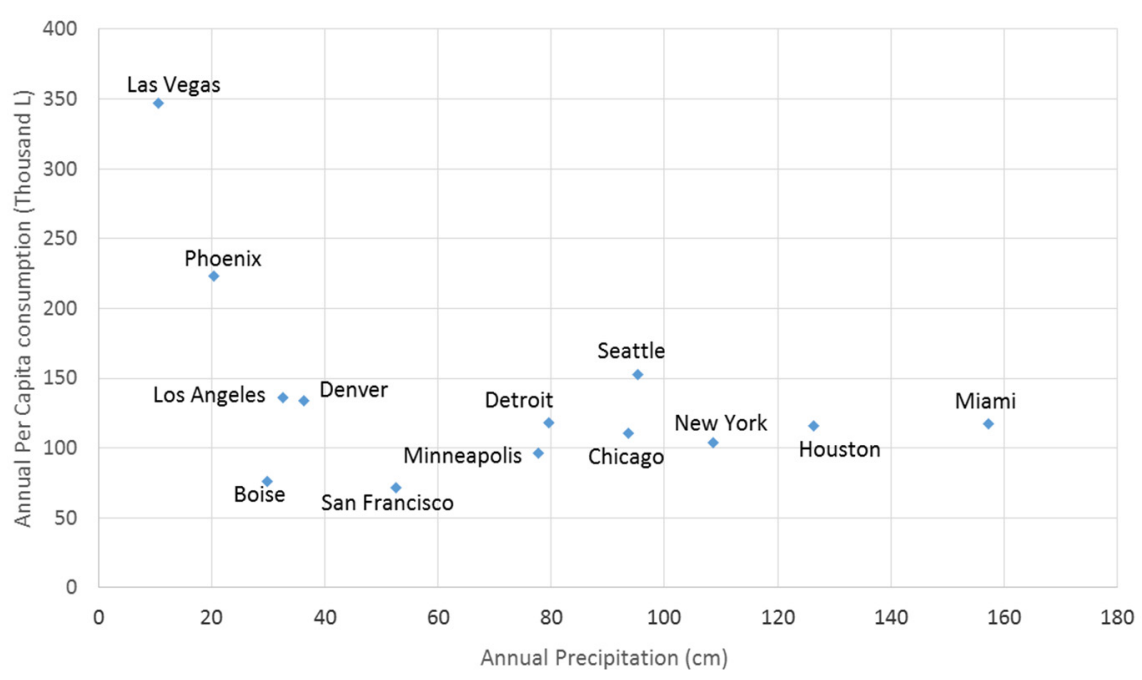

Figure 2: Correlation of water consumption and precipitation in each city.

indoor water use including leak is 261 liters (69.3 gallons) per capita per day. However, the outdoor water uses vary drastically depending on climate and resident's behaviour; 38\% of residents never irrigate outdoor landscape, while those owning single-family homes in desert climates expend substantial volumes of water in maintaining gardens, decorative fountains, and grass lawns. Thus in this study, we estimated non-drinking water consumption of our test homes including toilet and outdoor uses by deducting the average drinking water volume from the total household water consumption.

\section{Non-drinking water self-sufficiency}

Depending on climate, rainwater harvesting meets a range of fractions of the annual non-drinking water demands of a single-family home in America. In Miami, which typically sees the most precipitation, rooftop rainwater harvesting could provide about $100 \%$ of annual non-drinking water needs, followed by Houston with $82 \%$ and New York with $79 \%$. In arid cities, the annual water selfsufficiencies are estimated at $2 \%$ in Las Vegas, $7 \%$ in Phoenix and $18 \%$ in Los Angeles (see Figure 3).

\subsection{Monthly non-drinking water self-sufficiency analysis}

In a given climatic region, precipitation varies during the course of a year. Depending on their seasonal climatic patterns, some regions have rainy months in summer, while others experience more precipitation in winter. Thus, the water self-sufficiency of homes that utilize rainwater harvesting varies during the course of a year and depends largely on the climate. 


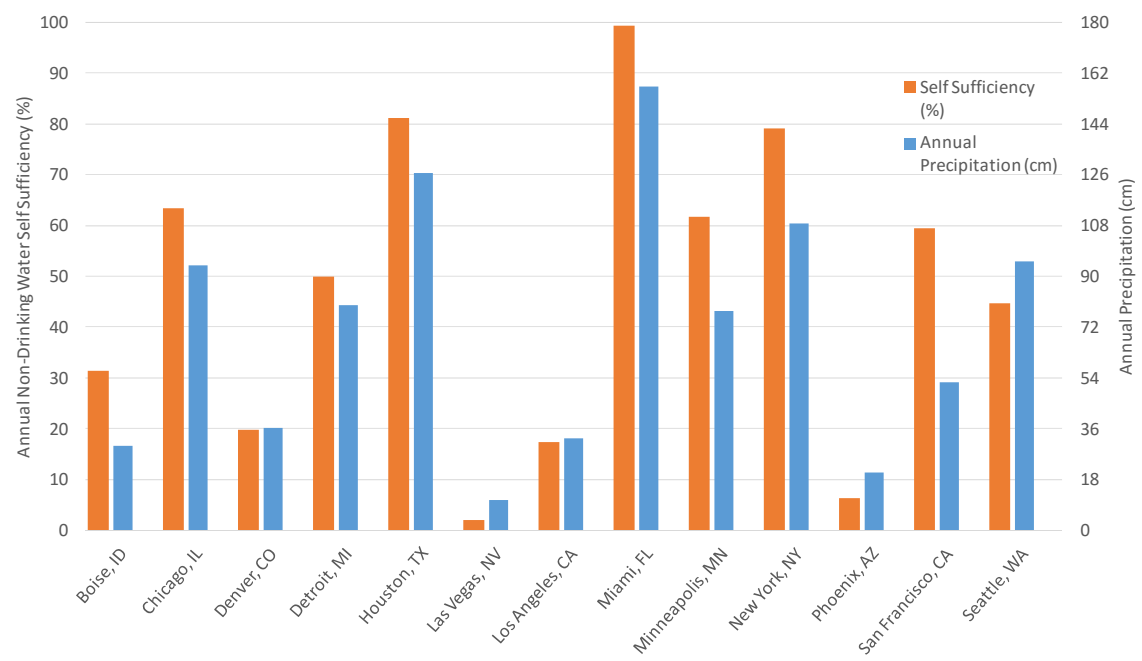

Figure 3: Annual non-drinking water self-sufficiency and precipitation.

\subsubsection{Southeast regions}

In Miami and Houston, representing the humid southeast, the non-drinking water self-sufficiencies are significantly higher in May through October. The test home in Miami shows a distinct disparity in self-sufficiency over the course of the year. In June and September, the non-drinking water self-sufficiencies of the test home ranges between $30-50 \%$, while in winter months, it is less than $15 \%$. The home in Houston does not show as noticeable an imbalance as in Miami, though the seasonal variation still exists. In summer months, the self-sufficiency fluctuates between $20 \%$ and $30 \%$, while in winter months it hovers around $18 \%$ (see Figure 4).

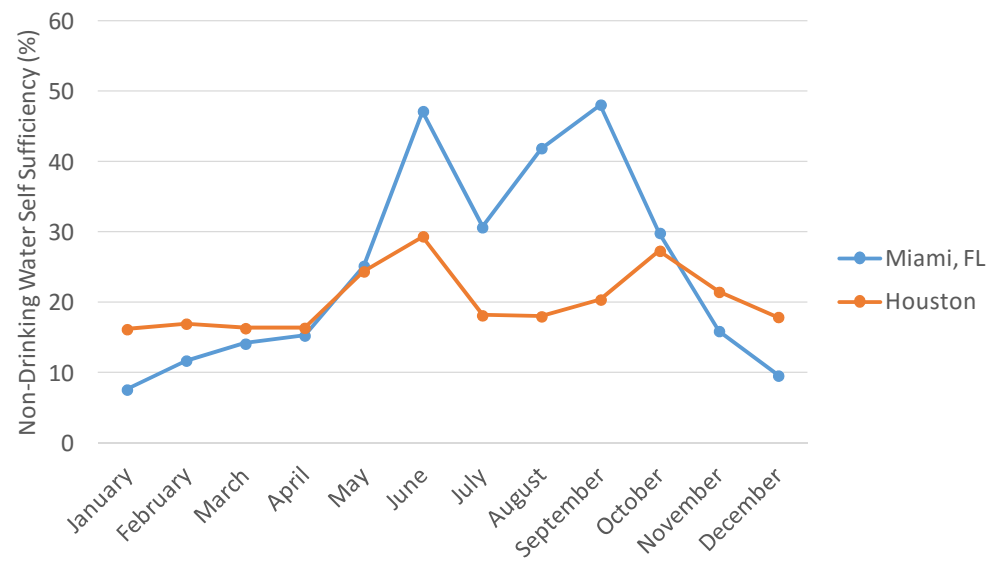

Figure 4: Monthly non-drinking water self-sufficiency of test homes in humid Southeast cities. 


\subsubsection{Pacific regions}

In the Pacific Northwest coastal regions, the seasonal variation of precipitation is very pronounced (see Figure 5). Due to climatic characteristics of the Pacific Northwest, high levels of precipitation are recorded in winter months, with little to none in the summer months. In San Francisco, rainwater harvesting meets over $34 \%$ of the non-drinking water demand in December through February, while in May through September the water self-sufficiency is less than 5\%. Seattle experiences similar seasonal disparity in self-sufficiency, but lesser in magnitude. In November through January, Seattle's non-drinking water self-sufficiency is over $18 \%$, while in May through September, it is less than $8 \%$.

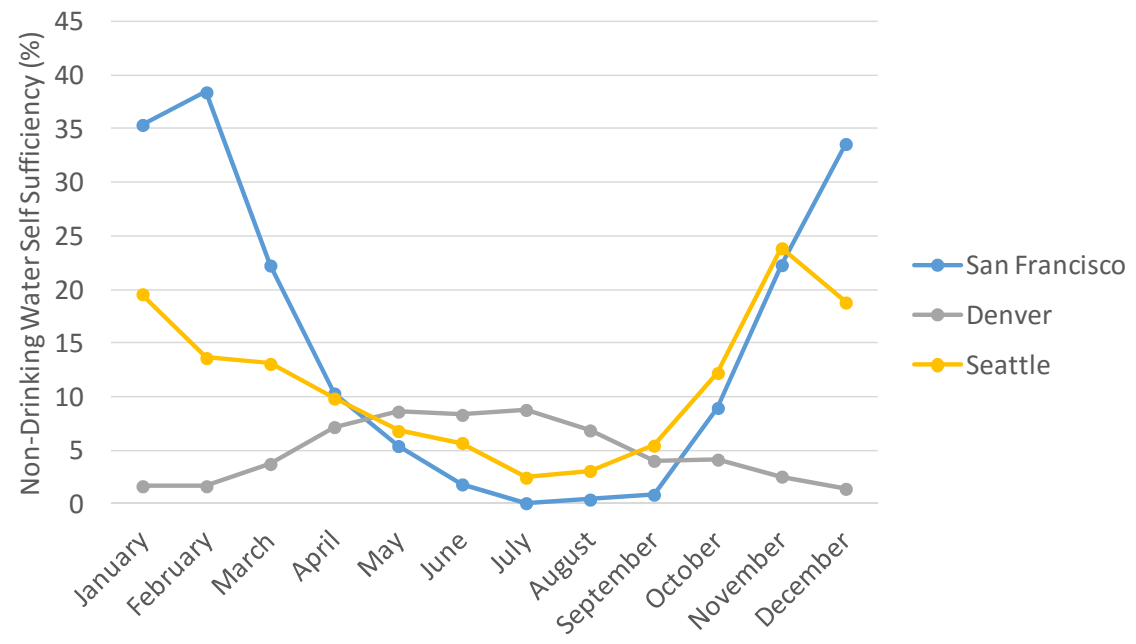

Figure 5: Monthly non-drinking water self-sufficiency of test homes in Pacific cities.

\subsubsection{Northeast and Midwest regions}

The monthly water self-sufficiencies of Northeast and Midwestern cities are typically higher in the summer and lower in the winter (see Figure 6). In New York, however, the seasonal variations are much less than those of Midwestern cities such as Chicago, Detroit and Minneapolis. This could be due to higher levels of precipitation in winter months in New York. The uniformity of seasonal and monthly water self-sufficiency will allow a cistern to be utilized near full capacity throughout the year, avoiding under-utilization in dry seasons. On the other hand, in Minneapolis, the water self-sufficiency is less than 7\% in December through February, and is higher than $18 \%$ in May through September.

\subsubsection{Southwestern Desert regions}

Monthly non-drinking water self-sufficiencies of the Southwest regions generally fall below 15\%, as expected for desert conditions (see Figure 7). In Los Angeles, the water self-sufficiency in December through February is relatively high for the region, ranging from $8 \%$ to $14 \%$. Though the contribution of rainwater harvesting 


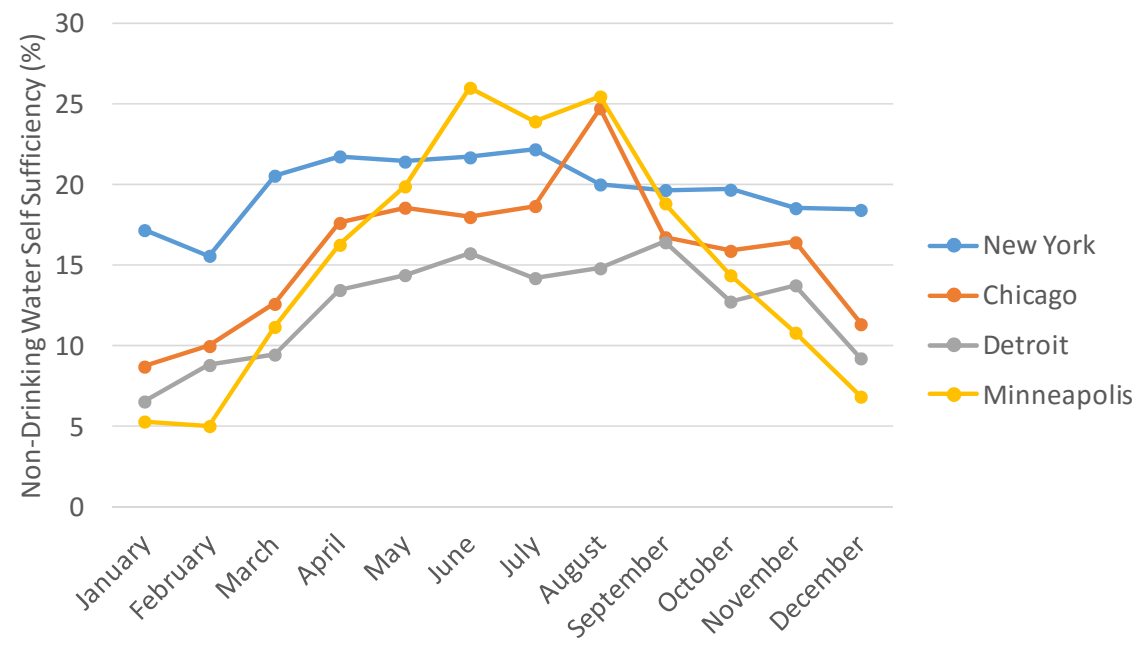

Figure 6: Monthly non-drinking water self-sufficiency in New York and Midwestern cities.

to the water self-sufficiency of residential buildings is lower than other climatic regions, water is still a very precious resource in desert climates. The $8 \%$ to $14 \%$ potential non-drinking water self-sufficiency during those three months in Los Angeles should therefore be regarded as a valuable resource. In Phoenix, the monthly water self-sufficiencies generally fall around 3\%, though dropping to almost zero in April through June. In Las Vegas, the water self-sufficiency falls below $1.5 \%$ throughout the year. Based on the water self-sufficiencies of these three cities, it is debatable whether it is worthwhile to invest in rainwater harvesting systems in hot and arid climates. One could argue that the high value of water in arid regions justifies investing in a rainwater harvesting system. A rainwater harvesting system could also reduce reliance on water imported or channelled hundreds of miles from other regions.

\section{Strategies for increasing water self-sufficiency}

Strategies for enhancing water self-sufficiency can be categorized into two major categories: increasing onsite water production and water usage conservation. A combination of these two strategies can increase the water self-sufficiency of buildings in any climate zone.

The most obvious strategy for increasing onsite water production with a rainwater harvesting system is enlarging the catchment area. The test home used in this study does not have any eaves, which realistically is undesirable, not only for rainwater harvesting but also for sun-shading, water drainage and waterproofing. Adding eaves to the roof enlarges the rainwater catchment area. The addition of 1.2 meters ( 4 feet) of wraparound eaves on all four sides of the test building enlarges the rainwater catchment area $26.9 \%$. Accordingly, the water 


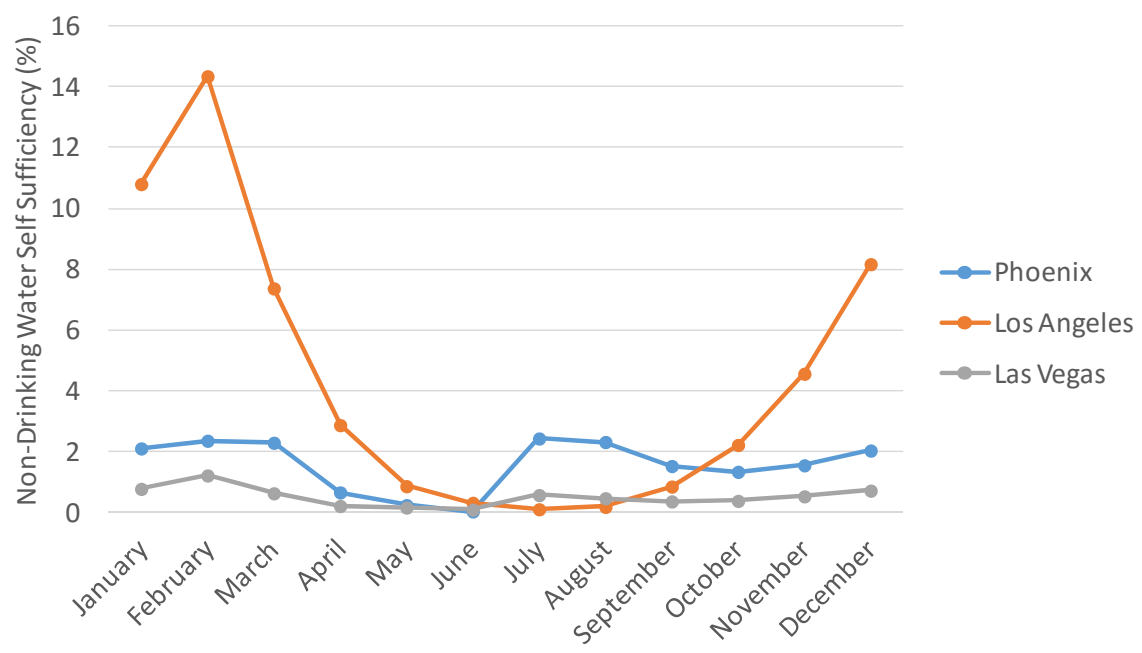

Figure 7: Monthly non-drinking water self-sufficiency of test homes in Southwest desert cities.

self-sufficiency of the standard single-family home will increase by the same percentage in all regions. For example, the annual non-drinking water selfsufficiency in Phoenix will increase from 7\% and 8.9\%. Extending the eaves even further out from the walls would provide another increase in the volume of collected rainwater. It is impractical, however, to extend eaves deeper than 1.2 meters in typical building designs.

An alternative to increasing the catchment areas is to collect rainwater from other surfaces such as adjustable rainwater catchment shelters or tents. Rainwater retention ponds or underground storage systems that channel and store storm water from ground surfaces are already employed in some municipalities.

With average consumption around 300 liters (80 gallons) per capita per day, the current levels of American water consumption are much higher than many other countries. This finding is consistent with data published by US Geological Survey and US EPA $[8,9]$. In the long run, it unsustainable to maintain the current level of US domestic water consumption, especially in Las Vegas and Phoenix. Water conservation is essential in achieving water self-sufficiency in the building sector.

\section{Conclusions}

The water self-sufficiency of buildings that utilize rainwater harvesting is a function of two principal factors: water demand and precipitation. The selfsufficiency is approximately linearly proportional to precipitation and is inversely proportional to water demand. In other words, the higher the precipitation, the higher the water self-sufficiency, and the higher the demand, the lower the water self-sufficiency. 
In order to increase water self-sufficiency, it is necessary to consider both supply and demand. With current American levels of domestic water consumption, it is infeasible to achieve water self-sufficient single-family homes even in the regions of the highest precipitation. The non-drinking water self-sufficiencies in arid cities often fall below 2\%. The two most arid cities, Phoenix and Las Vegas, consume the highest volume of water among the 13 cities studied. As the biological and hygienic water needs of people at home including drinking, cooking, dishwashing, and bathroom use are generally similar regardless of climates, the high water demands in arid cities can be ascribed mostly to nonessential water consumption such as landscape irrigation or swimming pool use. Such water-consumptive life style and site features are unsustainable and will not allow for water self-sufficiency. Conservation methods that drastically reduce the current level of water consumption are essential for $100 \%$ self-sufficient buildings. Incorporating water recycling technologies or enlarging rooftop catchment surfaces by extending eaves from the roof increases on-site water production. Ultimately to attain water self-sufficient homes, however, alternative catchment areas must be utilized, such as collecting storm water from ground surfaces of a building lot in a retention pond or underground cisterns. This study reveals that when these conservation and harvesting strategies are implemented together, water self-sufficient single-family homes will be possible in many non-desert regions of the United States.

\section{References}

[1] David J. Sample, Jia Liu and Sai Wang. 2013. Evaluating the Dual Benefits of Rainwater Harvesting Systems using Reliable Analysis. Journal of Hydrologic Engineering, Vol. 18, Issue 10.

[2] Martin E Buchberger and Chakraborty, D. 2015. Reliability of Harvested Rainfall as an Auxilliary Source of Non-potable Water. Procedia Engineering, 10.1016/j.proeng.2015.08.954, pp. 1119-1128.

[3] Lizarraga-Mendiola, Liiana et al. 2015. Estimating the Rainwater Potential per Household in an Urban Area: Case Study in Central Mexico. Water.

[4] Chao-Hsien Liaw and Y-Chung Chiang. 2014. Framework for Assessing the Rainwater Harvesting Potential of Residential Buildings at a National Level as an Alternative Water Resource for Domestic Water Supply in Taiwan. Water, Vol. 6, Issue 10.

[5] American Housing Survey. 2005. US Census Bureau. www.census.gov/ programs-surveys/ahs/data/2005/2005-ahs-national-puf-microdata.html.

[6] 1981-2010 Monthly Normals Documentation. National Oceanic and Atmospheric Administration, National Centers for Environmental Information. www.ncdc.noaa.gov/cdo-web/.

[7] Estimated Use of Water in the United States County-Level Data for 2010. United States Geological Survey. http://water.usgs.gov/watuse/data/2010/.

[8] United States Geological Survey, the USGS Water Science School. http://water.usgs.gov/edu/qa-home-percapita.html. 
[9] United States Environmental Protection Agency. Water Sense, An EPA Partnership Program. www3.epa.gov/watersense/pubs/indoor.html.

[10] Peter W. Mayer et al. 1999. Residential End Uses of Water. AWWA Research Foundation and AWWA. Denver, Colorado.

[11] B. D. Inskeep and S. Attari. 2014. The Water Shortlist: The Most Effective Actions US Household Can Take to Curb Water Use. Environment Journal, July-August. 